\title{
Time-Domain Nuclear Magnetic Resonance (TD-NMR) and Chemometrics for Determination of Fat Content in Commercial Products of Milk Powder
}

\author{
Paloma Andrade Martins Nascimento and Paulo Lopes Barsanelli \\ Universidade Estadual Paulista "Júlio de Mesquita Filho," Instituto de Química, Departamento de Química Analítica, \\ Rua Professor Francisco Degni, 55, Araraquara, SP 14800-060, Brazil \\ Ana Paula Rebellato and Juliana Azevedo Lima Pallone \\ Universidade Estadual de Campinas, Faculdade de Engenharia de Alimentos, Departamento de Ciência de Alimentos, \\ Campinas, SP 13083-962, Brazil \\ Luiz Alberto Colnago \\ Embrapa Instrumentação, Rua Quinze de Novembro 1452, São Carlos, SP 13561-206, Brazil \\ Fabíola Manhas Verbi Pereira ${ }^{1}$ \\ Universidade Estadual Paulista “Júlio de Mesquita Filho," Instituto de Química, Departamento de Química Analítica, \\ Rua Professor Francisco Degni, 55, Araraquara, SP 14800-060, Brazil
}

This study shows the use of time-domain (TD)-NMR transverse relaxation $\left(T_{2}\right)$ data and chemometrics in the nondestructive determination of fat content for powdered food samples such as commercial dried milk products. Most proposed NMR spectroscopy methods for measuring fat content correlate free induction decay or echo intensities with the sample's mass. The need for the sample's mass limits the analytical frequency of NMR determination, because weighing the samples is an additional step in this procedure. Therefore, the method proposed here is based on a multivariate model of $T_{2}$ decay, measured with Carr-Purcell-Meiboom-Gill pulse sequence and reference values of fat content. The TD-NMR spectroscopy method shows high correlation $(r=0.95)$ with the lipid content, determined by the standard extraction method of Bligh and Dyer. For comparison, fat content determination was also performed using a multivariate model with near-IR (NIR) spectroscopy, which is also a nondestructive method. The advantages of the proposed TD-NMR method are that it (1) minimizes toxic residue generation, (2) performs measurements with high analytical frequency (a few seconds per analysis), and (3) does not require sample preparation (such as pelleting, needed for NIR spectroscopy analyses) or weighing the samples.

$\mathrm{P}$ owdered milk is obtained by dehydrating whole, skimmed, or semiskimmed cow's milk using appropriate technological processes and is fit for human consumption.

Guest edited as a special report on "Application of Multivariate Statistical Techniques in Chromatographic and Spectroscopic Fingerprinting of Complex Food and Environmental Samples" by Paweł K. Zarzycki.

${ }^{1}$ Corresponding author's e-mail address: fabiola@iq.unesp.br

This research was supported by the Fundunesp (Process 0268/001/14), National Council for Scientific and Technological Development (Process 445729/2014-7), São Paulo Research Foundation (Process 2012/20264-0 and 2016/00779-6), and Finep.

DOI: $10.5740 /$ jaoacint. 16-0408
The chemical constituents of dried milk products are lactose, proteins, minerals, and fat, as well as vitamins A, B, and D. However, several factors, such as breeding programs, animal health, and feed or weather conditions may influence dried milk composition $(1,2)$.

Among the components of milk, lipids are a class of molecules with different functions (3) that are insoluble in water but soluble in organic solvents. Lipids are essential for the synthesis of cell membranes and plasma and participate in the formation of structural components of all tissues, as well as being the largest energy reserves in the body (4).

Thus, lipids are an important source of energy for the newborn (5) and participate in the protection of vital organs and the transport of fat-soluble vitamins (vitamins A, D, E, and $\mathrm{K} ; 6,7)$. Furthermore, lipids play essential roles in neuronal growth, signal transduction, the excitability of neural membranes, and retinal development, as well as in the expression of genes that regulate cellular differentiation and growth (8).

Milk lipids consist of fatty acids belonging to two groups: saturated (single bonds) and unsaturated fatty acids (with one or more double bonds). Saturated and monounsaturated fatty acids can be synthesized in the body, unlike polyunsaturated fatty acids, which are considered essential fatty acids (9).

Linoleic and $\alpha$-linolenic acids are prominent polyunsaturated fatty acids due to their importance for the synthesis of lipids in tissues, in the regulation of various metabolic processes of transport and excretion (10), and because they are essential for the healthy growth of infants and children (11).

The lipid content provides between 45 and $55 \%$ of the total energy in human milk, and a similar content can be found in industrialized infant formula (4). Although the fatty acids in human milk meet these requirements for the infant, in certain circumstances, it is necessary to use powdered milk formulas as a replacement or as a complement to human milk (11).

According to Klein (12), the lipid content in infant formula for preterm infants should be between 4.4 and $5.7 \mathrm{~g} / 100 \mathrm{kcal}$, providing approximately $52 \%$ of the total energy. For premature babies, the recommended values should be between 4.4 and $6.4 \mathrm{~g} / 100 \mathrm{kcal}$, providing approximately 40 to $60 \%$ of the total energy. 
Milk is a highly complex matrix, and for lipid analysis, it is relevant to emphasize that nonpolar bioactive components present at very low levels (13) have a strong influence on milk quality. For the determination of these components, separation methods and techniques that are more sensitive than near-IR (NIR) or time-domain (TD)-NMR spectroscopy are required.

The standard wet analytical method for the determination of lipid content, such as Bligh and Dyer's (14), requires a high volume of organic solvents, generates toxic waste, and is laborious for the analytical chemist. Thus, TD-NMR spectroscopy has been an alternative technique for fat analysis (15). The advantages of TD-NMR when compared with lipid extraction or NIR spectroscopy methods are that it is rapid, noninvasive, and provides analysis of the bulk composition; has no need for sample preparation; and does not depend on the sample's surface morphology.

The novelty of the current study lies in directly assessing the variations in the fat present in powdered samples (i.e., regular dried milk and infant formula) using TD-NMR spectroscopy in combination with chemometrics, without weighing the samples. In addition, we demonstrate in this study that a single model is able to predict the content of fat in the previously mentioned samples, considering that these analytical matrixes show similarity in chemical composition, homogeneity, and particle size. Likewise, the data were also compared using NIR spectroscopy after multivariate calibration. The data obtained using both methods (TD-NMR and NIR spectroscopy) were evaluated using the standard method of lipid extraction as the reference (14).

\section{Experimental}

\section{Samples}

Dried milk and infant formula samples were purchased locally and consisted of commercial dairy goods from three worldknown manufacturers. The samples included two skimmed and one whole powdered milk products, four milk formulas, and seven milk compounds with vegetable oils and skimmed milk in their composition.

\section{TD-NMR Measurements}

The NMR analyses of powdered milk samples were performed at $0.23 \mathrm{~T}\left(9 \mathrm{MHz}\right.$ for $\left.{ }^{1} \mathrm{H}\right)$ using a benchtop SLK $200 \mathrm{NMR}$ spectrometer (Spinlock Magnetic Resonance Solutions, Córdoba, Argentina). The probe coil (detector) is a cylinder $13 \mathrm{~mm}$ in height and $30 \mathrm{~mm}$ in diameter. The sample holder was filled with dried sample up to $13 \mathrm{~mm}$ (detector height). The sample's mass ranged from 9.0 to $14 \mathrm{~g}$ depending on the sample density. The NMR analyses were performed in three authentic replicates per sample (one reading per replicate, total of 42 signals).

The NMR signals were acquired using the Carr-PurcellMeiboon-Gill (CPMG) pulse sequence using $\pi / 2$ and $\pi$ pulses of 6.2 and $12 \mu \mathrm{s}$, respectively; an echo time of $500 \mu \mathrm{s}$; and 1500 echoes and four scans. The analyses were performed with the samples at $23^{\circ} \mathrm{C}$.

\section{NIR Measurements}

NIR spectra were collected in three authentic replicates per sample (one reading per replicate, total of 42 spectra) using an
FT-IR Spectrum 1050 spectrometer (PerkinElmer, Waltham, MA). Diffuse reflectance spectra were recorded in the UV-Vis/ NIR region for wavelengths between 190 and $2500 \mathrm{~nm}$ at a spectral resolution of $2 \mathrm{~cm}^{-1}$. The $\log (1 / \mathrm{R})$ spectra were referred to as absorbance spectra for convenience.

\section{Reference Methods}

The total lipid content was determined using the Bligh and Dyer extraction method (14). Moisture content was determined by using an official AOAC Method for drying samples (16). Both methods were carried out in authentic triplicate per sample.

\section{Multivariate Models}

To predict the fat content in the powdered samples, multivariate calibration models were developed based on the partial least-squares (PLS) chemometric technique, available in Pirouette 4.5 rev. 1 software (Infometrix, Bothell, WA). The data matrix was organized in 14 rows (mean of the three signals per sample) corresponding to the samples and 1500 columns for the TD-NMR CPMG signals as independent variables (X matrix); the values of fat content obtained by standard methods were used as dependent variables (y vector).

NIR data were organized in 14 rows (mean of the three spectra) and 1156 data points (independent variables).

\section{Results and Discussion}

In this study, two spectroscopic techniques, NIR and TD-NMR, were applied to measure the fat content of commercial powdered dried milk products without the use of solvents or other chemical products. Figure 1 shows the percentage $(\mathrm{g} / 100 \mathrm{~g})$ fat and moisture content determined experimentally. The values ranged from 0.75 to $26 \%$ fat and from 1.9 to $3.9 \%$ moisture.

The content values that were displayed on the product labels and those obtained from the lipid extraction were highly correlated, as indicated by the regression model and coefficient of correlation (r). However, the reference values and those from the labels showed significant differences at the $95 \%$ confidence level using a paired $t$-test for multiple samples, where the calculated $t$-value was 3.67 and the tabulated $t$-value was 2.16 for $13 \mathrm{df}(P<0.05)$, as shown in Table 1 . Therefore, it was more appropriate to use the fat content values obtained by the Bligh and Dyer analysis carried out for each sample as the reference values. The difference between the reference and the reported fat content could be due to the label reflecting an average of analyzed fat content values and not necessarily the result from each package. Another unresolved issue was the fact that in the case of the two products of skimmed milk, the reference values were 0.75 and 1.3 , not 0.0 as reported in the nutritional facts. From here to the end, the reference values for multivariate models of fat calibration model were those obtained by Bligh and Dyer analysis.

For comparison, NIR spectroscopy, a consolidated spectroscopy technique that has been used for the determination of protein content $(17)$, as well as adulterants $(18,19)$ and calcium (20) in powdered milk, was applied for the fat determination in the studied samples. 


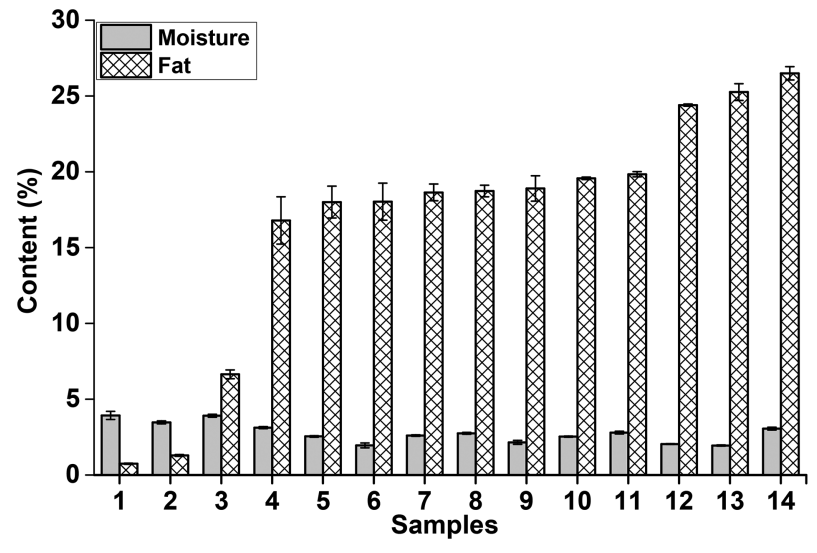

Figure 1. Centesimal analysis for content of fat and moisture in powdered milk samples.

Figure 2 shows the NIR spectral bands related to fat absorption that are characterized by the symmetric vibrations of the $\mathrm{CH}$ single bond and the $\mathrm{C}=\mathrm{O}$ double bond for the second overtone in the 2200-2489 $\mathrm{nm}$ range and the 1145-1200 $\mathrm{nm}$ range, respectively. The intensities of the bands at the wavelengths of 1728,2308 , and $2348 \mathrm{~nm}$ decrease with increasing fat content $(21,22)$. For instance, using NIR spectroscopy, when the samples containing half cream and half milk were analyzed, the same regions of absorption for lipids (1730, 1778, 2312, and $2354 \mathrm{~nm}$ ) were similarly reported. Therefore, the bands at 1730 and $1778 \mathrm{~nm}$ correspond to the first overtone of the $\mathrm{CH}_{2}$ stretching vibrations of fat, and the bands at 2312 and $2354 \mathrm{~nm}$ are due to the bending of $\mathrm{CH}_{2}$ and $\mathrm{CH}_{3}$ in the fat molecules. Thus, the spectral region from 750 to $1000 \mathrm{~nm}$ was avoided because

Table 1. Parameters from the reference method of lipid extraction (Bligh and Dyer) and the multivariate models for fat determination

\begin{tabular}{|c|c|c|c|}
\hline Parameter & $\begin{array}{l}\text { Nutrition } \\
\text { information from } \\
\text { the labels versus } \\
\text { Bligh and Dyer }\end{array}$ & $\begin{array}{l}\text { Bligh and Dyer } \\
\text { versus NIR }\end{array}$ & $\begin{array}{l}\text { Bligh and Dyer } \\
\text { versus TD-NMR }\end{array}$ \\
\hline $\begin{array}{l}\text { Correlation } \\
\text { coefficient }\end{array}$ & 0.99 & 0.99 & 0.95 \\
\hline $\mathrm{LV}^{a}$ & $-^{b}$ & 3 & 4 \\
\hline $\begin{array}{l}\text { Explained } \\
\text { variance, \% }\end{array}$ & - & $\sim 95$ & $\sim 100$ \\
\hline RMSEC, $\%{ }^{c}$ & - & 1.4 & 3.1 \\
\hline $\begin{array}{l}\text { Regression } \\
\text { model }\end{array}$ & $y=0.89 x+0.68$ & $y=0.98 x+0.37$ & $y=0.90 x+1.66$ \\
\hline $\begin{array}{l}\text { Time of } \\
\text { measuring, s }\end{array}$ & $10800(\sim 3 h)$ & $270(\sim 5 \min )$ & 1 \\
\hline $\begin{array}{l}\text { Estimated cost } \\
\text { of analysis } \\
\text { considering the } \\
\text { reagents, US\$ }\end{array}$ & 11 & 0 & 0 \\
\hline $\begin{array}{c}t_{\text {calc }}\left(t_{\text {crit }}=2.16\right. \\
95 \%, 13 \mathrm{df})^{d}\end{array}$ & 3.67 & $2.42 \times 10^{-6}$ & $1.15 \times 10^{-6}$ \\
\hline \multicolumn{4}{|c|}{ a $\quad$ LV = Latent variable. } \\
\hline \multicolumn{4}{|c|}{$b \quad-=$ Not available } \\
\hline \multicolumn{4}{|c|}{ c RMSEC = Root mean square error of calibration. } \\
\hline \multicolumn{4}{|c|}{$t_{\text {calc }}=$ Calculated $t$-value; $t_{\text {crit }}=$ tabulated $t$-value. } \\
\hline
\end{tabular}

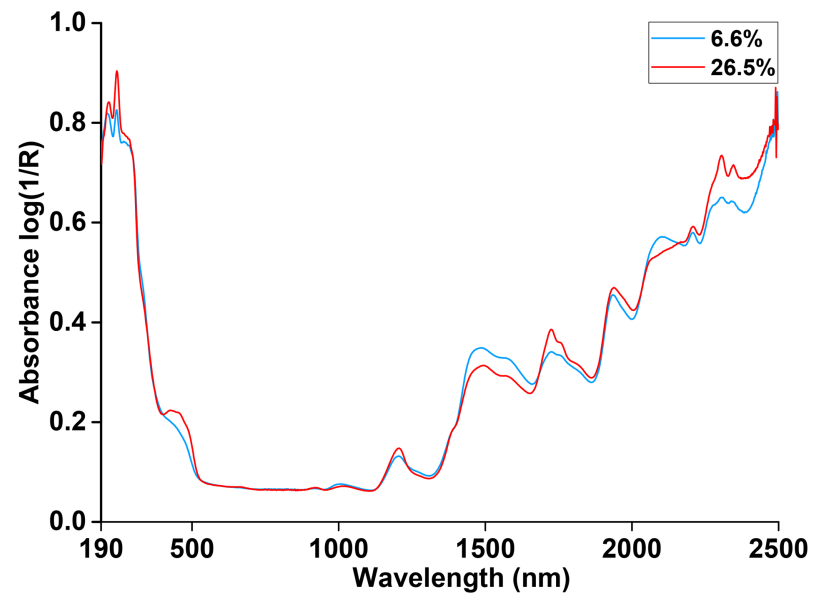

Figure 2. NIR spectra acquired for powdered milk samples with distinct percentages $(\mathrm{g} / 100 \mathrm{~g})$ of fat content.

no useful analytical information was provided. In addition, it was found that a reduced number of variables improved the speed of the calculations for the development of chemometrics models.

The average of the spectra was used to select the wavelength range between 1000 and $2500 \mathrm{~nm}$. Physical effects, such as particle size and the surface roughness of solid samples, are responsible for the scattering of radiation (23). To minimize the influence of light scattering and the baseline drift, the following transformations were tested on the spectra: (1) the first derivative with a five-point window based on a SavitzkyGolay polynomial filter and (2) multiplicative scatter correction (MSC) combined with the first derivative with a five-point window based on a Savitzky-Golay polynomial filter.

The Savitzky-Golay derivative method performs a smoothing of the spectra before the calculation of the derivative, thereby reducing the effect on the $\mathrm{S} / \mathrm{N}$ derivatives obtained using finite differences. The key idea is to correct vertical variations ( $y$-axis), and it means that after this transformation, each spectrum must begin at the same position considering the response (absorbance). A symmetrical smoothing window was used, requiring that the number of data points on each side of the center point be the same. As a number of points on each end of the spectrum are neglected, the number of missing points is equal to the number of smoothing points used minus 1 . For the first derivative, a first- and second-degree polynomial will give the same response as the third- and fourth-degree polynomials (24). MSC also corrects the offset of baseline considering horizontal variations ( $x$-axis) and provides separation of the chemical light absorption from the physical light scatter. In Figure 2, it is possible to verify that each band had a distinct baseline; after this transformation, these differences visualized in the NIR spectra profile should be compensated. For the calculations, the sample spectrum is corrected at each wavelength by first subtracting the intercept and then dividing by the slope; both parameters are from the mean spectrum of included samples (25).

The best result for the PLS model developed with NIR data were obtained using MSC and the Savitzky-Golay first derivative, with a RMSEC of $1.4 \%$, as shown in Table 1 . The spectra in the 1000 to $2500 \mathrm{~cm}^{-1}$ range, with 751 variables, were applied for the model. The prediction values were calculated using three LVs with a 95\% explained variance and are highly 
correlated $(r=0.99)$ with the reference values. The equation of the regression model for the predicted values of fat content and those measured with Bligh and Dyer's method is shown in Table 1 .

For TD-NMR methods, it is common to use univariate calibration curves between the intensity of the free induction decay or the echo signals versus sample weight to determine the fat content in samples with low water content (26-28).

However, multivariate methods using chemometrics combined with NMR relaxation decay data obtained with CPMG pulse sequence is a rapid and robust method for fat and moisture content determination $(15,29)$. The NMR signal is obtained directly in powdered milk products without solubilization in water or other solvent $(27,28)$. The NMR relaxation decay is an intrinsic property of the sample that does not depend on sample compaction or weight. After optimization of the multivariate model, the use of wet analysis and methods that apply solvent extraction is minimized.

For the multivariate calibration model, the decay of the TDNMR signals for each sample was normalized by the maximum intensity (Figure 3), and the independent variables were meancentered. Next, all signals began at the same point (i.e., 1), and had a mean value equal to 0 .

Figure 3 shows the normalized amplitude of CPMG decays of dried milk samples containing 6.6 and 26.5\% lipids and demonstrates the strong effect of the lipid content of dried milk on the CPMG decay. This effect is the property used for the multivariate modeling. The moisture content did not interfere in the analyses because the moisture variation was very small (Figure 1).

According to Table 1, four LVs were needed for the TDNMR multivariate model that represented approximately $100 \%$ of explained variance, and the RMSEC was $3.1 \%$ with high correlation $(r=0.95)$. Here, the improvement due to our method is the much shorter time of measurement, with only $1 \mathrm{~s}$ required for TD-NMR analysis per sample, compared to $270 \mathrm{~s}$ (approximately $5 \mathrm{~min}$ ) for the NIR spectra acquisition and approximately $3 \mathrm{~h}$ for the lipid extraction using the reference method.

An additional advantage verified with TD-NMR spectroscopy combined with chemometrics is the low error for samples with a

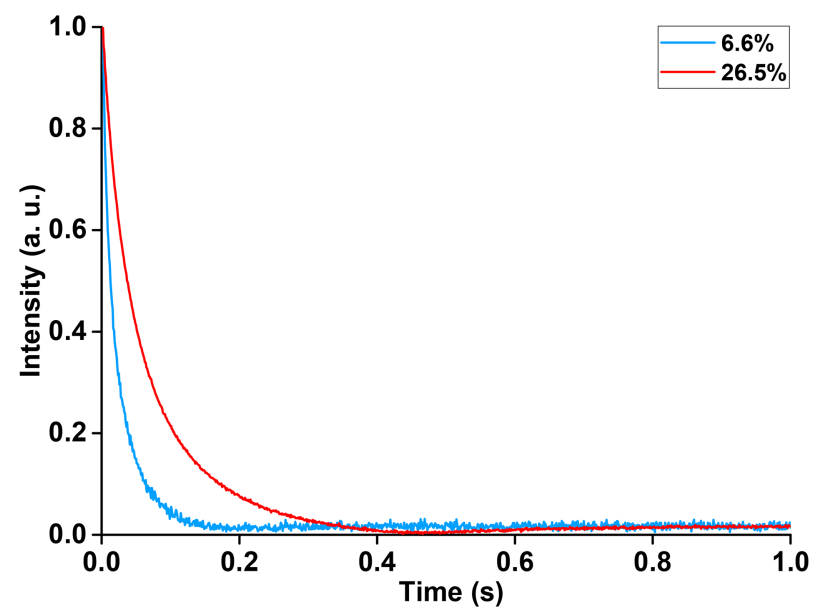

Figure 3. Relaxation decays from CPMG pulse sequence for powdered milk samples with distinct percentages $(\mathrm{g} / 100 \mathrm{~g})$ of fat content. fat content of $0.75 \%$. The absolute error (i.e., the value computed using the reference value from Bligh and Dyer's method minus the value predicted by the PLS model, for the same sample) was 0.03 , whereas for the NIR method, the absolute error was 0.7 . A further advantage of TD-NMR analysis is that it provides for assessment of samples in bulk.

The evaluation of the data was laborious for the NIR spectroscopy method and required sophisticated preprocessing such as MSC associated with the first derivative, the consideration of variations in particle size, and a highly experienced analytical chemist. In addition, the main drawback of the standard method is exposure to toxic solvents, such as chloroform, and waste generation from the fraction of methanol.

Figure 4A reinforces that the predicted values for the TDNMR method tend to be very similar to both the reference values obtained from the lipid extraction and to those obtained by the NIR method (Figure 4B).

\section{Conclusions}

The potential of the model developed using TD-NMR CPMG and a multivariate model for the prediction of fat content in commercial powdered milk samples is likely to be extended to a wider range of products and used mainly in industrial QC; this
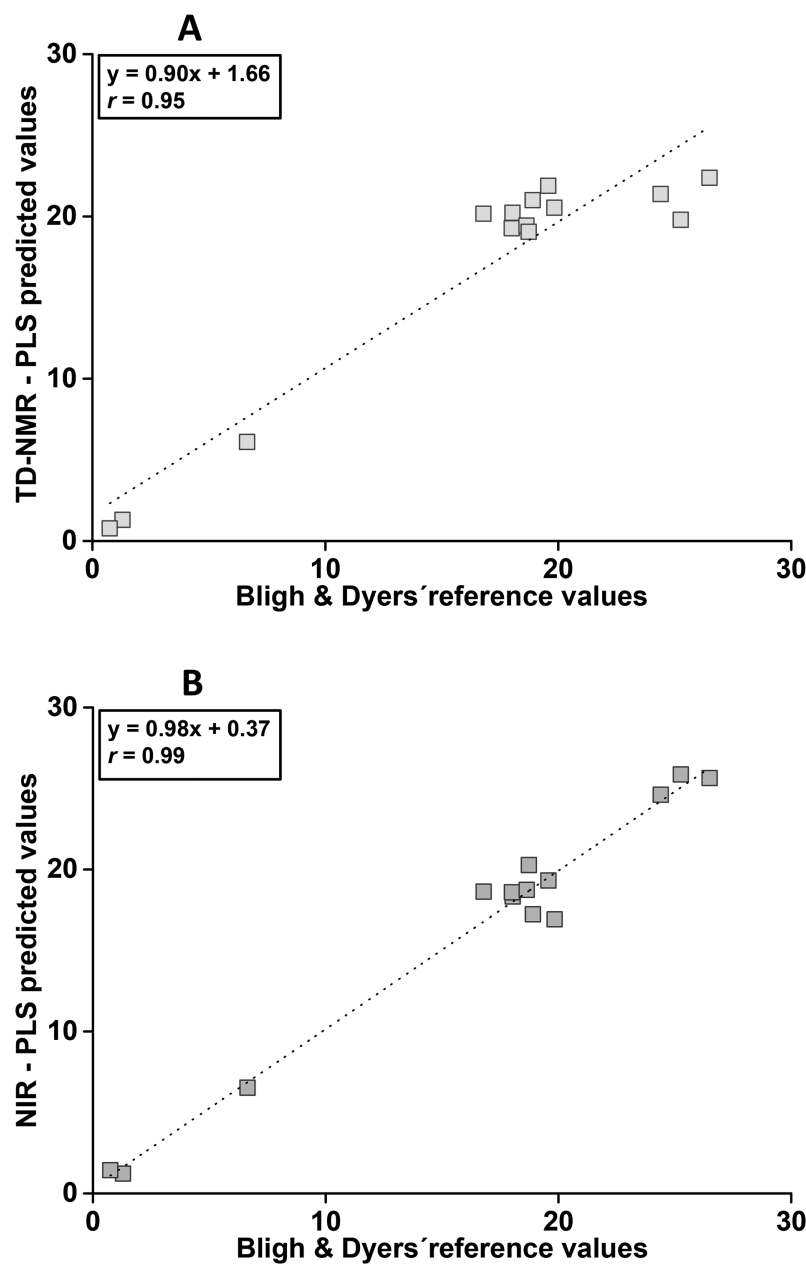

Figure 4. Performance of prediction for fat content between Bligh and Dyer's method and those predicted by multivariate models of (A) TD-NMR and (B) NIR spectroscopy. 
will reduce the generation of waste by decreasing the need for common classical methods of wet analysis.

The accuracy of the data, demonstrated by the comparison of the developed method with the consolidated technique of NIR and the reference method of lipid extraction, reinforces the robustness and applicability of TD-NMR spectroscopy for QC purposes, considering that the time required for the analysis is less than $1 \mathrm{~s}$ and that there is no requirement for weighing the samples.

\section{References}

(1) Walstra, P., Geurts, T.J., Noomen, A., Jellema, A., \& Boekel, M.A.J.S. (2005) Dairy Technology: Principles of Milk Properties and Processes, Marcel Dekker, New York, NY

(2) Inácio, M.R.C., Moura, M.F.V., \& Lima, K.M.G. (2011) Vib. Spectrosc. 57, 342-345. doi:10.1016/j.vibspec.2011.07.002

(3) Lucena, R., Gallego, M., Cárdenas, S., \& Valcárcel, M. (2003) Anal. Chem. 75, 1425-1429. doi:10.1021/ac020553n

(4) Uauy, R., \& Catillo, C. (2003) J. Nutr. 133, 2962S-2972S

(5) Martini, M., Salari, F., \& Altomonte, I. (2016) Crit. Rev. Food Sci. Nutr. 56, 1209-1221. doi:10.1080/10408398.2012.758626

(6) de Castro, H.F., Mendes, A.A., Dos Santos, J.C., \& de Aguiar, C.L. (2004) Quim. Nova 27, 146-156. doi:10.1590/ S0100-40422004000100025

(7) Rucker, R.B., Morris, J., \& Fascetti, A.J. (2008) in Clinical Biochemistry of Domestic Animals, 6th Ed., J. Kaneko, J.W. Harvey, \& M.L. Bruss (Eds), Academic Press, San Diego, CA, pp 695-730. doi:10.1016/B978-0-12-370491-7.00023-4

(8) Cermenati, G., Mitro, N., Audano, M., Melcangi, R.C., Crestani, M., Fabiani, E., \& Caruso, D. (2015) Biochim. Biophys. Acta 1851, 51-60. doi:10.1016/j.bbalip.2014.08.011

(9) Alabdulkarim, B., Bakeet, Z.A.N., \& Arzoo, S. (2012) J. King Saud Univ. Sci. 24, 319-329. doi:10.1016/j.jksus.2012.03.001

(10) Connor, W.E. (2000) Am. J. Clin. Nutr. 71, 171-175

(11) Romeu-Nadal, M., Chávez-Servín, J.L., Castellote, A.I., Rivero, M. \& López-Sabater, M.C. (2007) Food Chem. 100, 756-763. doi:10.1016/j.foodchem.2005.10.037

(12) Klein, C.J. (2002) J. Nutr. 132, 1395S-1549S
(13) German, J.B., \& Dillard, C.J. (2006) Crit. Rev. Food Sci. Nutr. 46, 57-92. doi:10.1080/10408690590957098

(14) Bligh, E.G., \& Dyer, W.J. (1959) Can. J. Biochem. Physiol. 37, 911-917. doi:10.1139/059-099

(15) Pereira, F.M.V., Rebellato, A.P., Pallone, J.A.L., \& Colnago, L.A. (2015) Food Control 48, 62-66. doi:10.1016/j. foodcont.2014.02.028

(16) Official Methods of Analysis (1980) 17th Ed., AOAC INTERNATIONAL, Gaithersburg, MD

(17) Wu, D., He, Y., Feng, S., \& Sun, D.-W. (2008) J. Food Eng. 84, 124-131. doi:10.1016/j.jfoodeng.2007.04.031

(18) Kasemsumran, S., Thanapase, W., \& Kiatsoonthon, A. (2007) Anal. Sci. 23, 907-910. doi:10.2116/analsci.23.907

(19) Borin, A., Ferrão, M.F., Mello, C., Maretto, D.A., \& Poppi, R.J. (2006) Anal. Chim. Acta 579, 25-32. doi:10.1016/j.aca.2006.07.008

(20) Wu, D., Nie, P., He, Y., \& Bao, Y. (2012) Food Bioprocess Technol. 5, 1402-1410. doi:10.1007/s11947-010-0492-4

(21) Veselá, A., Barros, A.S., Synytsya, A., Delgadillo, I., Copíková, J., \& Coimbra, M.A. (2007) Anal. Chim. Acta 601, 77-86. doi:10.1016/j.aca.2007.08.039

(22) Li-Chan, E.C.Y., Griffiths, P.R., \& Chalmers, J.M. (2010) Applications of Vibrational Spectroscopy in Food Science, Vol. I: Instrumentation and Fundamental Applications, John Wiley \& Sons, Ltd. Chichester, UK

(23) Souza, A.M., \& Poppi, R.J. (2012) Quim. Nova 35, 223-229. doi:10.1590/S0100-40422012000100039

(24) Rinnan, A., Berg, F.V.D., \& Engelsen, S.B. (2009) Trends Analyt. Chem. 28, 1201-1222. doi:10.1016/j.trac.2009.07.007

(25) Geladi, P., MacDougall, D., \& Martens, H. (1985) Appl. Spectrosc. 39, 491-500. doi:10.1366/0003702854248656

(26) Colnago, L.A., Azeredo, R.B.V., Marchi Netto, A., Andrade, F.D., \& Venâncio, T. (2011) Magn. Reson. Chem. 49, S113-S120 doi:10.1002/mrc.2841

(27) Maher, A.D., \& Rochfort, S.J. (2014) Metabolites 4, 131-141. doi: $10.3390 /$ metabo4010131

(28) Davenel, A., Schuck, P., Mariette, F., \& Brulé, G. (2002) Lait 82, 465-473. doi:10.1051/lait:2002024

(29) Pereira, F.M.V., Hashimoto, J.C., Pallone, J.A.L., \& Colnago, L.A. (2015) Food Anal. Methods 8, 122-125. doi:10.1007/s12161-014-9877-8 